\title{
Unusual Behavior Detection of Korean Cows using Motion Vector and SVDD in Video Surveillance System
}

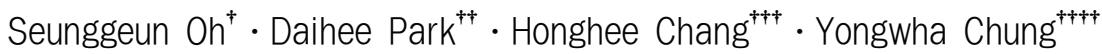

\begin{abstract}
Early detection of oestrus in Korean cows is one of the important issues in maximizing the economic benefit. Although various methods have been proposed, we still need to improve the performance of the oestrus detection system. In this paper, we propose a video surveillance system which can detect unusual behavior of multiple cows including the mounting activity. The unusual behavior detection is to detect the dangerous or abnormal situations of cows in video coming in real time from a surveillance camera promptly and correctly. The prototype system for unusual behavior detection gets an input video from a fixed location camera, and uses the motion vector to represent the motion information of cows in video, and finally selects a SVDD (one of the most well-known types of one-class SVM) as a detector by reinterpreting the unusual behavior into an one class decision problem from the practical points of view. The experimental results with the videos obtained from a farm located in Jinju illustrate the efficiency of the proposed method.
\end{abstract}

Keywords : Video Surveillance System, Unusual Behavior Detection, Motion Vector, Support Vector Data Description

\section{움직임 벡터와 $\mathrm{SVDD}$ 를 이용한 영상 감시 시스템에서 한우의 특이 행동 탐지 \\ 오 승 근 ${ }^{\dagger}$ 박 대 희 ${ }^{\dagger \dagger}$. 장 홍 희 ${ }^{\dagger+\dagger} \cdot$ 정 용 화 ${ }^{\dagger+\dagger}$}

\begin{abstract}
요 약
한우 발정기의 조기 탐지는 축산 농가의 경제성을 향상시키는 매우 중요한 연구 과제 중 하나이다. 이를 위한 다양한 방법들이 제안되었으 나, 현재까지도 시스템의 경제성 문제를 포함한 조기 발정 탐지 및 탐지 정확도 등에 여전히 취약한 점이 있는 것이 사실이다. 본 논문에서는 감시카메라 환경에서 축사내 승가 행동을 포함하는 한우의 특이 행동들을 탐지하는 다중 객체의 특이 행동 탐지 프로토타입 시스템을 제안한 다. 다중 객체의 특이 행동 탐지란 감시카메라로부터 유입되는 영상에서 다중 객체가 위험에 처한 상황 혹은 비정상적인 행동들을 신속하고 정 확하게 탐지하는 분야를 말한다. 제안된 시스템은 한우 축사에 고정 설치된 카메라의 입력 동영상으로 부터 움직임 벡터 정보를 이용하여 영상 내의 움직임 정보를 추출·표현하였으며, 특이 행동의 판별 문제를 실용적 차원의 단일 클래스 분류 문제로 재해석하여 단일 클래스 SVM의 대 표적 모델인 SVDD를 탐지기로 설계하였다. 실제로 진주에 위치한 한 축사에서 취득한 한우 암소의 영상 정보를 이용하여 본 논문에서 제안한 시스템의 성능을 실험적으로 검증한다.
\end{abstract}

키워드 : 비디오 감시 시스템, 특이 행동 탐지, 움직임 벡터, Support Vector Data Description

\section{1. 서 론}

암소 발정기의 조기 탐지는 축사 관리에 있어서 매우 중

\footnotetext{
※ This research was supported by Advanced Production Technology Development Program(Ministry for Food, Agriculture, Forestry, and Fisheries, Republic of Korea) and BK21 Plus Program.

† 준 회 원: 고려대학교 컴퓨터정보학과 박사과정

†† 정 회 원 고려대학교 컴퓨터정보학과 교수

††† 정 회 원: 경상대학교 축산학과 교수

꽤 종신회원: 고려대학교 컴퓨터정보학과 교수 논문접수: 2013년 5월 30일

수 정 일 : 1 차 2013년 7월 8 일

심사완료 : 2013년 7월 30일

* Corresponding Author: Yongwha Chung(ychungy@korea.ac.kr)
}

요한 요소이며, 탐지 실패는 한우 개체 수 및 우유 생산량 의 감소로 이어진다. 따라서 이는 농가의 경제성과 직결되 는 매우 중요한 문제이며 반드시 해결해야만 하는 문제이 다. 발정기를 탐지하는 방법은 사람이 직접 개입하는 전통 적인 방법들(눈으로 감지, 발색제, 크레용을 사용하는 방법 등) 외에 최근 IT 농·축산 분야에서도 암소의 발정기 조기 탐지 문제를 해결하기 위한 다양한 연구들이 진행되고 있다 [1]. 이는 호르몬 변화로 인해 발정기에 동반되는 암소들의 특이 행동들 또는 신체 정보의 변화를 이용하는 것으로, 암 소의 체온 변화를 이용하는 기술[2] 및 소리 정보를 이용하 여 발정기를 탐지하는 방법 등이 소개되고 있다[3-5]. 그러 
나 매번 탐지기를 탈부착하는 번거러움 외에 오탐지(false positive)의 비율이 높다는 문제점이 여전히 존재한다.

반면, IT관련 보안 감시 분야의 연구는 감시 카메라로부 터 획득한 멀티미디어 데이터로부터 원하는 장면 및 정보를 검색하는 단순한 보안 검색 시스템에서부터, 동영상에서 객 체의 움직임을 적극적으로 검출하고 위험 상황 혹은 비정상 적인 상황을 미리 인지하여 알람(alert)을 통해 관리자에게 알리거나, 실제 발생한 사건 또는 이벤트들을 이해하기 위 해 자동으로 객체를 인식 및 식별하고 추적하는 등 고수준 의 의미 정보를 찾기 위한 연구들까지 다양하게 진행되고 있다[6-7]. 이러한 연구들 중 본 논문의 연구 주제인 감시카 메라 환경에서의 다중 객체(한우들)의 특이 행동 탐지는 감 시카메라로부터 유입되는 감시 영상에서 단일 객체들의 세 부 움직임 추적이 아닌 다중 객체가 위험에 처한 상황 혹은 특이 상황을 신속하고 정확하게 탐지하는 분야이다.

감시카메라 환경에서 특이 행동을 탐지하는 연구의 가장 중요한 두 가지 요소 기술은 영상내의 움직임을 표현하는 방법과 특이 행동들을 탐지하는 알고리즘이다. 먼저, 영상내 의 움직임을 표현하는 방법은 최근 움직임 벡터를 선호하는 추세로 진행되고 있다[8-10]. 반면, 탐지기와 관련된 선행 연구들은 $\mathrm{GMM}$ (Gaussian Mixture Model)이나 LDA(Latent Dirichlet Allocation)와 같은 전통적인 확률론적 패턴인식 알고리즘[11-12]을 비롯하여, 최근에는 패턴 분류 및 함수 근사 등의 문제에서 우수한 성능을 보이는 $\mathrm{SVM}$ (Support Vector Machine)을 집단 행동 기반의 감시시스템에 적용하 는 연구들이 흥미롭게 발견된다[13].

일반적으로 번식우의 발정기는 약 18 시간 정도 지속이 되 는데, 이때의 특징은 다른 소에게 승가를 허용하고 활동량이 증가하고 자주 울부짖으며, 불안한 모습을 하고 사람이 다가 서면 느리게 피하고 눈치를 보며 먹이를 먹지 않는다. 또한 대음순이 촉촉하게 되고 붉어지며 음순에서 맑은 점액이 흘 러나오고 안구가 약간 충혈이 되기도 한다. 특히, 승가당하는 암소의 발정기 정확도는 약 $65 \sim 98 \%$ 에 이른다고 알려져 있 다[14]. 본 논문에서는 발정우의 승가 행동을 포함하는 한우 의 특이 행동들을 탐지하는 문제를 감시카메라 환경에서 다 중 객체의 특이 행동 탐지 문제로 해석하여 문제를 해결하고 자 한다. 위에서 언급한 바와 같이, 감시카메라 환경에서 특 이 행동을 탐지하는 연구의 가장 중요한 두 가지 요소 기술 중, 영상내의 움직임을 표현하는 방법으로는 움직임 벡터를 이용하여 영상내의 움직임 정보를 추출·표현하였으며, 특이 행동의 판별 문제를 실용적 차원의 단일 클래스 분류 문제로 재해석하여 단일 클래스 SVM의 대표적 모델인 SVDD(Support Vector Data Description)를 탐지기로 설계하 였다. 따라서, 본 논문에서 제안하는 감시카메라 환경에서의 비정상 행동 탐지 시스템은 탐지기로 $\mathrm{SVDD}$ 를 사용하여 정 상 데이터만을 학습함으로써, 감시카메라 환경에서의 비정상 데이터의 구성문제를 해결함과 동시에 정상 데이터가 아닌 데이터는 추가 학습을 하지 않음으로 불필요한 연산을 줄인 다. 또한, 상황에 따라 새로운 클래스의 비정상 데이터가 추 가되더라도 이미 정상 데이터만으로 학습을 마친 $\mathrm{SVDD}$ 를
통해 추가 학습과정 없이 자동으로 비상상황 탐지를 수행함 으로써, 시스템의 점증적 갱신 및 확장을 보장한다.

본 논문의 구성은 다음과 같다. 2장에서는 비정상 행동 탐지와 관련된 연구방법론의 문헌고찰을 간략하게 서술하고, 3장에서는 본 논문에서 제안하는 비정상 행동 탐지 프로토 타입 시스템에 대해 상세히 기술한다. 4장에서는 실험 결과 및 성능 분석을, 마지막으로 5장에서는 결론 및 향후 연구 과제에 대해 논한다.

\section{2. 관련 연구}

감시카메라 환경에서 집단 내의 비상상황을 탐지하는 연 구는 집단 내의 밀집도를 이용하는 정적(static) 방법과 집단 내의 움직임 정보에 기초한 동적(dynamic) 방법으로 분류할 수 있다[15]. 정적 방법은 하나의 영상 장면에 일정 이상의 객체가 유입되어 미리 정해둔 임계값과 차이가 날 때를 이상 상황으로 결정하는 방법이며, 동적 방법은 하나의 영상 장면 에서 객체들의 움직임이 급변하게 발생할 때를 이상 상황으 로 결정하는 방법이다. 반면, 움직임을 표현하는 방법으로는 객체 추적 방법과 움직임 기반 접근 방법이 있다[16-17]. 객 체 추적방법은 움직이는 객체의 궤도 분석에 초점을 맞추어 비정상 행동을 탐지하기 때문에 실세계 상황의 복잡한 장면 에서 움직이는 모든 객체에 대한 추적을 해야만 한다. 이는 과도한 계산량을 필요로 할 뿐만 아니라 정확한 결과 값을 얻기도 힘들다는 단점이 있다. 움직임 기반 접근 방법은 차 영상(background subtraction), 옵티컬 플로우(optical flow), 혹은 움직임 벡터를 이용하는 방법으로 트래킹 과정을 요구 하지 않기 때문에 신속하게 비정상 행동을 탐지할 수 있는 방법이다[18]. 본 논문에서는 영상의 움직임 벡터를 이용하여 감시카메라 환경에서 유입되는 동영상으로부터 움직임 정보 를 추출 및 표현(움직임 기반 접근 방법)하고, 이 움직임 정 보가 급격하게 변화하는 상황을 이상 상황으로 결정하는 동 적 연구방법론을 취한다.

본 논문과 관련된 대표적 선행 연구들을 정리하면 다음과 같다. Mehran 등[11]은 집단 에너지(social force)를 통해 단 행동을 모델링하였으며 옵티컬 플로우를 사용하여 움직임 정 보를 측정하고, $\mathrm{LDA}$ 모델로 비정상 행동을 탐지하는 시스템 을 제안하였다. Shi 등[12]은 움직임 벡터와 위상 상관도 (phase correlation)를 결합하여 움직임 정보를 측정하고, 확 률적 모델인 $\mathrm{GMM}$ 을 이용한 모델링을 통해 실시간으로 비 상상황을 탐지하는 시스템을 제안하였다. 이와 같은 GMM이 나 $\mathrm{LDA}$ 등은 학습 이론 중 학습오류(empirical error)를 최소 화하는 경험적 위험 최소화 원칙(empirical risk minimization)을 적용한 것이기 때문에 새로운 데이터가 나 타나면 시스템의 성능이 갑자기 나빠진다는 문제점을 지니고 있다. 반면 SVM 계열의 알고리즘은 구조적 위험 최소화 원 칙(structural risk minimization)의 개념을 기초로 하기 때문 에 일반화 성능이 우수하며, 비선형 분리 문제와 같은 복잡 한 분류문제를 해결하기 위한 다양한 커널들을 제공한다[19]. 


\section{3. 감시카메라 환경에서 한우의 특이 행동 탐지 시 스템}

본 논문에서 제안하는 감시 카메라 환경에서 한우의 특이 행동 탐지 시스템의 구조는 Fig. 1과 같다. 이는 1개의 오프 라인 처리 모듈인 SVDD 학습 모듈과 2개의 온라인 처리 모듈인 Momentum Calculator, 그리고 특이 행동 탐지 모듈 로 구성된다. 각 모듈의 기능은 다음과 같다. 1) SVDD 학 습 모듈에서는 정상 데이터 훈련 집합만으로 오프라인 상에 서 학습을 실시한다. 2) Momentum Calculator에서는 움직 임 벡터를 움직임 정보의 량으로 변환한다. 3) 특이 행동 탐 지 모듈에서는 학습이 완료된 $\mathrm{SVDD}$ 를 이용하여 유입되는 데이터가 정상 상황의 범주에서 벗어나는지를 실시간으로 판단하여, 정상 상황의 범주에서 벗어나면 이를 $\mathrm{CCTV}$ 관리 자에게 통보함으로서 사건·사고에 신속하게 대처한다.

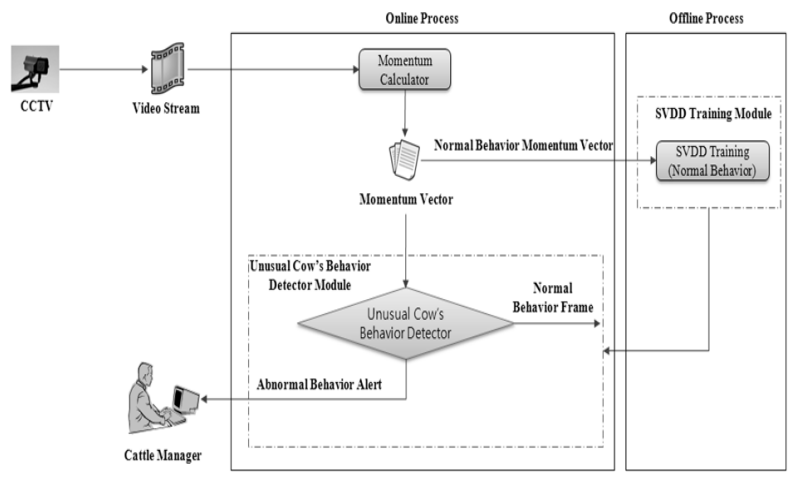

Fig. 1. Overall structure of the cow's unusual behavior detection system

\subsection{Momentum Calculator}

영상의 움직임 벡터의 크기와 방향은 Fig. 2 와 같이 각각 $m$ 과 $\theta$ 로 표현된다(식 (1)참조).

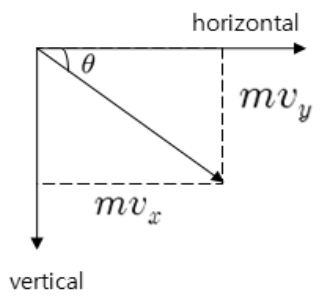

Fig. 2. Magnitude and direction of motion vectors

$$
m=\sqrt{\left(m v_{x}^{2}+m v_{y}^{2}\right)}
$$

여기서, $m v_{x}$ 와 $m v_{y}$ 는 움직임 벡터의 각각 가로축과 세 로축 성분이다.
Momentum Calculator에서는 실시간으로 유입되는 비디 오 스트림으로부터 7 개 프레임 간격으로 식 (1)을 이용하여 움직임 벡터의 크기와 방향을 특징 벡터로 표현한다.

\subsection{SVDD 기반의 특이 행동 탐지}

감시카메라 환경에서 특이 행동 탐지 시스템의 가장 중요 한 목적은 유입되는 영상으로부터 신속하게 특이 상황여부를 판별하는 것이다. 비정상 집단행동 여부의 판별 문제는 집단 행동의 식별 문제와는 달리 유입된 영상이 정상 집단행동의 범주에 속하는지 아닌지를 판별하는 이진 클래스 분류 (binary class classification) 문제로 볼 수 있다. 그러나 비정 상 집단행동 탐지를 수행하기 위해서는 정상 집단행동만으로 기계학습을 수행한 후, 실시간으로 유입된 영상이 정상 집단 행동 범주에 속하는지 벗어나는지를 확인하는 것이 보다 실 용적이다. 결국 이는 단순히 실시간으로 유입되는 영상의 이 상 여부를 확인하는 과정이므로, 이진 클래스 분류 문제가 아닌 단일클래스 분류(one class classification) 문제로 보는 것이 합리적이다. 따라서 본 논문에서는 단일 클래스 SVM 의 가장 대표적인 방법론인 $\mathrm{SVDD}$ 를 이용하여 비정상 집단 행동 여부를 신속하게 판단하고자 한다. $\mathrm{SVDD}$ 를 이용하여 비정상 상황을 탐지하는 방법은 다음과 같다. 학습과정에서 정상 영상으로 구성된 데이터만을 이용하여 특징 공간에서 영상 신호 영역을 포함하는 원형체를 학습한다. 즉 결정함수 식을 도출한다(식 6 참조). 인식과정에서는 입력된 테스트 영 상 신호가 원형체 안에 포함되면 정상 상황으로 인식하며, 포함되지 않은 영상 신호는 비정상 상황으로 판단한다.

$\mathrm{SVDD}$ 를 이용한 단일 클래스 분류 방법은 다음과 같다 [20]. $d$-차원 입력공간에 존재하는 $N$ 개의 데이터로 구성되 는 학습 데이터의 집합 $D=\left\{x_{i} \mid i=1, \cdots, N\right\}$ 에 대해서 $R^{d}$ 위 에 정의되는 중심이 $a$ 이고 반경이 $R$ 인 원형체 $B$ 를 이용하 여 학습 클래스의 존재 영역을 표현한다. 이 경우 각 학습 데이터 $x_{i}$ 와 중심 $a$ 사이의 거리가 $R$ 을 초과하는 경우에는 적절한 벌점(penalty)을 부과하는 전략을 사용하여 다음과 같은 최적화 문제를 정의한다.

$$
\begin{aligned}
& \min L_{0}\left(R^{2}, a, \xi\right)=R^{2}+C \sum_{i=1}^{N} \xi_{i} \\
& \text { s.t. }\left\|x_{i}-a\right\|^{2} \leq R^{2}+\xi_{i}, \xi_{i} \geq 0, \forall i
\end{aligned}
$$

여기에서, $\xi_{i}$ 는 $i$-번째 학습 데이터 $x_{i}$ 가 원형체에서 벗 어나는 벌점이며, $C$ 는 반지름과 벌점항의 상대적 중요성을 조정하는 상수(trade-off constant)이다. 라그랑제 함수 (Lagrange function) $L$ 을 이용하여 위 문제에 대응하는 쌍 대 문제(dual problem)를 구한다. 쌍대 문제는 다음과 같은 $\mathrm{QP}($ Quadratic Programming) 문제로 정리된다.

$$
\begin{aligned}
& \min _{a} \sum_{i=1}^{N} \sum_{j=1}^{N} \alpha_{i} \alpha_{j}\left\langle x_{i}, x_{j}\right\rangle-\sum_{i=1}^{N} \alpha_{i}\left\langle x_{i}, x_{j}\right\rangle \\
& \text { s.t. } \quad \sum_{i=1}^{N} \alpha_{i}=1, \alpha_{i} \in[0, C], \forall i .
\end{aligned}
$$


학습이 끝난 후 적용 과정에서 결정함수는 다음과 같이 정의된다.

$$
\begin{aligned}
f(x)= & R^{2}-\|x-a\|^{2} \\
= & R^{2}-\left(\langle x, x\rangle-2 \sum_{i=1}^{N} \alpha_{i}\left\langle x_{i}, x\right\rangle\right. \\
& \left.+\sum_{i=1}^{N} \sum_{j=1}^{N} \alpha_{i} \alpha_{j}\left\langle x_{i}, x_{j}\right\rangle\right) \geq 0
\end{aligned}
$$

가우시안 커널을 사용할 경우 최적화 문제 식 (5)는 다음 과 같이 보다 간단한 형태로 단순화 될 수 있다.

$$
\begin{aligned}
& \min _{a} \sum_{i=1}^{N} \sum_{j=1}^{N} \alpha_{i} \alpha_{j}\left\langle x_{i}, x_{j}\right\rangle \\
& \text { s.t. } \sum_{i=1}^{N} \alpha_{i}=1, \alpha_{i} \in[0, C], \forall i .
\end{aligned}
$$

이 경우 커널 함수 $\Phi$ 도입후의 결정함수 식 (6)은 아래 의 식으로 대치된다.

$$
\begin{aligned}
f(x)= & R^{2}-\|\varnothing(x)-a\|^{2} \\
= & R^{2}-\left(1-2 \sum_{i=1}^{N} \alpha_{i} k\left(x_{i}, x\right)\right. \\
& \left.+\sum_{i=1}^{N} \sum_{j=1}^{N} \alpha_{i} \alpha_{j} k\left(x_{i}, x_{j}\right)\right) \geq 0
\end{aligned}
$$

\section{4. 실험 및 결과 분석}

본 논문에서 제안한 감시카메라 환경에서 한우의 특이 행 동 탐지 시스템의 성능 평가를 위하여 진주에 위치한 한 축 사에서 취득한 한우 암소의 영상 정보를 이용하여 실험하였 다. 정상 데이터와 특이 행동 데이터 모두 초당 24 개 프레 임으로 구성된 동영상으로부터 7개 프레임 간격으로 움직임 벡터를 추출하였다. 정상 데이터는 암소가 거닐거나 쉬고 있는 장면들로 3,000 개, 특이 행동 데이터는 승가 이벤트가 나타났을 때의 프레임 구간으로부터 추출된 움직임 벡터 286개와 뒷발을 차면서 흥분하여 뛰는 장면으로부터 추출한 움직임 벡터 134 개를 포함한 총 420개의 데이터로 실험을 수행했다. 이때 정상 데이터와 특이 행동 데이터 모두 $640 \times 480$ 크기를 갖는 원본 프레임으로부터 $8 \times 8$ 크기의 모션 블록을 사용하여 추출한 움직임 벡터 $(80 \times 60=4800$ 차원의 특 징 벡터)를 사용했으며, 식 (1)로 움직임 벡터의 크기와 방 향을 계산하였다. Fig. 3은 한우 축사에게 발정우가 다른 소 에게 승가를 허용하는 모습을 보여준다.

전체 정상 데이터 3,000 개 중 2,400 개로 학습 후 나머지 600 개의 정상 데이터와 420 개의 특이 행동 데이터를 이용하 여 교차 검증 방법으로 반복 실험을 수행하였다. 실험 결과 특이 행동 탐지율(UBDR: Unusual Behavior Detection Rate)은 평균 $96.4 \%, \mathrm{FPR}$ (False Positive Rate: 정상 행동이
특이 행동으로 오탐지된 비율)은 평균 $2.3 \%$, 그리고 $\mathrm{FNR}$ (False Negative Rate: 특이행동이 정상으로 오탐지된 비율)은 평균 $1.9 \%$ 의 만족스러운 실험 결과를 얻었다(식 (7) 참조). $\mathrm{SVDD}$ 의 상대적 중요성을 조정하는 상수(trade-off constant) C값은 0.1로 고정하였으며, SVDD의 매개변수 $\sigma$ 값은 1.7 로 설정하였다.

$$
U B D R=\frac{\sum_{i=1}^{m} T_{i}}{\sum_{i=1}^{n} I_{i}}, F P R=\frac{\sum_{i=1}^{k} P_{i}}{\sum_{i=1}^{l} N_{i}}, F N R=\frac{\sum_{i=1}^{n-m} F_{i}}{\sum_{i=1}^{n} I_{i}}
$$

위 식에서 $I$ 는 특이 행동 데이터, $T$ 는 특이 행동 데이터 를 정확히 특이 행동으로 분류한 데이터, $N$ 은 정상 행동 데 이터, $P$ 는 정상 행동 데이터를 특이 행동으로 분류한 데이 터, $F$ 는 특이 행동 데이터를 정상으로 판단한 데이터를 의 미한다.

본 논문에서 제안한 방법의 실험 결과를 Table 1에 정리 하였고, 제안된 방법과 기존 방법론들과의 성능 비교는 Table 2에 요약하였다. 특히 본 연구의 선행 연구로 수행한 소리 신호를 이용한 발정기 특이음 탐지와는 유사한 정확도 를 나타내며, 소리와 영상 정보의 상호보완적인 측면을 감 안할 때 두 정보를 모두 이용하면 보다 완벽한 정확도를 얻 을 수 있을 것으로 기대된다.

앞에서 언급한 바와 같이 관리자에 의한 승가당하는 암소 의 육안 관찰만으로도 발정기 정확도는 약 $65 ~ 98 \%$ 에 이른 다고 알려져 있다. 가장 합리적인 발정 관찰 주기는 1 일 2 회 관찰(새벽과 저녁시각)하는 방법으로, 특히 밤 12시부터 새벽 6시까지 사이에 약 $43 \%$ 의 발정이 집중되므로 야간의 발정발견이 중요한 관건이다[14]. 결국, 승가당하는 암소의 자동 탐지만으로도 상당한 수준의 수정 적기 예측이 시스템 적으로 가능하나(본 연구의 정확도 $96.4 \%$ ), 관리자의 육안 관찰에 의존하는 현재의 방식으로는 번식우의 수정 적기를 정확하게 예측하는 것은 현실적으로 어렵다. 본 연구의 한 계점으로는 제한된 분량의 영상을 대상으로 실험했다는 것 과 주간 촬영 영상만을 사용했다는 점이다. 따라서 본 논문 에서 제안된 프로토타입의 시스템을 실세계에서 구현·운용 하기 위한 후속 연구에서 이 문제들을 풀어가고자 한다.

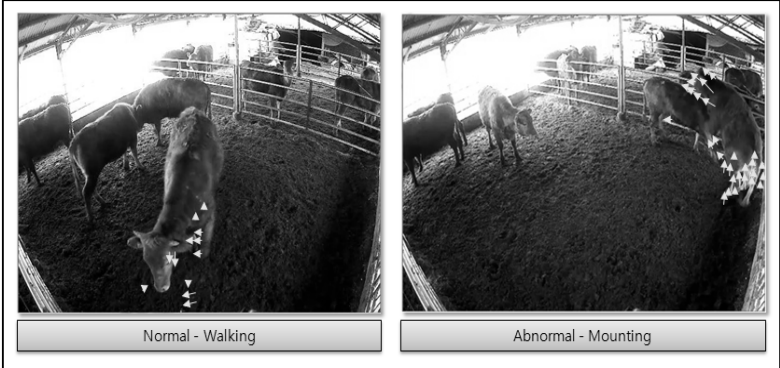

Fig. 3. Illustration of the mounting activity with motion vector 
Table 1. Performance evaluation of the proposed method

\begin{tabular}{|c|c|c|c|}
\hline$\sigma \quad$ Metrics & UBDR & FPR & FNR \\
\hline 1.7 & $96.4 \%$ & $2.3 \%$ & $1.9 \%$ \\
\hline
\end{tabular}

Table 2. Performance comparison with various methods

\begin{tabular}{|c|c|c|c|}
\hline Mothod & $\begin{array}{c}\text { Traditional } \\
\text { method[14] }\end{array}$ & $\begin{array}{c}\text { Chung et } \\
\text { al.[21] }\end{array}$ & $\begin{array}{c}\text { Proposed } \\
\text { method }\end{array}$ \\
\hline $\begin{array}{c}\text { Manual } \\
\text { /Automatic }\end{array}$ & Manual & Automatic & Automatic \\
\hline $\begin{array}{c}\text { Detection } \\
\text { Target }\end{array}$ & $\begin{array}{c}\text { Mounting/ } \\
\text { Unusual } \\
\text { Sound }\end{array}$ & $\begin{array}{c}\text { Unusual } \\
\text { Sound }\end{array}$ & $\begin{array}{c}\text { Mounting } \\
\text { or Running } \\
\text { Activities }\end{array}$ \\
\hline $\begin{array}{c}\text { Number of } \\
\text { Objects }\end{array}$ & Single Object & Single Object & $\begin{array}{c}\text { Multiple } \\
\text { Objects }\end{array}$ \\
\hline $\begin{array}{c}\text { Detection } \\
\text { Rate }\end{array}$ & $56 \%$ & $96.8 \%$ & $96.4 \%$ \\
\hline
\end{tabular}

\section{5. 결론 및 향후 연구}

본 논문에서는 발정우의 승가 행동을 포함하는 한우의 특 이 행동 탐지 문제를 감시카메라 환경에서 다중 객체의 특 이 행동 탐지 문제로 해석하여 해결하는 프로토타입 시스템 을 제안하였다. 제안된 시스템은 한우 축사에 고정 설치된 카메라의 입력 동영상으로 부터 움직임 벡터 정보를 이용하 여 영상내의 움직임 정보를 추출·표현하였으며, 특이 행동의 판별 문제를 단일 클래스 SVM의 대표적 모델인 SVDD로 탐지기를 설계하여 해결하였다. 저자가 아는 한 영상 정보 를 이용하여 소의 특이 행동을 자동으로 탐지하는 연구 결 과는 국내외를 불문하고 아직 보고된바 없으며, 실제로 진 주에 위치한 한 축사에서 취득한 한우의 영상 정보를 이용 하여 제안 시스템의 성능을 실험한 결과 만족할만한 성능을 얻을 수 있음을 검증하였다.

향후 연구 과제로는 본 논문에서 제안된 프로토타입의 시 스템을 실세계에서 구현·운용하기 위한 후속 연구들이 요구 되고, 영상 데이터뿐만 아니라 소리 데이터도 동시에 사용 하는 멀티모달 기반의 융합 연구 시 성능 개선이 기대된다.

\section{참 고 문 헌}

[1] M. Saint Dizier and S. Chastant Maillard, "Towards an automated detection of oestrus in dairy cattle," Reprod. Domes. Anim., Vol.47, No.6, pp.1056-1061, 2012.

[2] A. Fisher, R. Morton,J. Dempsey, J. Henshall, and J. Hill, "Evaluation of a new approach for the estimation of the time of the LH surge in dairy cows using vaginal temperature and electrodeless conductivity measurements," Theriogenology, Vol.70, No.7, pp.1065-1074, 2008.
[3] Y. Ikeda and Y. Ishii, "Recognition of two psychological conditions of a single cow by her voice," Comput. Electron. Agric., Vol.62, No.1, pp.67-72, 2008.

[4] G. Jahns, "Call recognition to identify cow conditions - a call-recogniser translating calls to text," Comput. Electron. Agric., Vol.62, No.1, pp.54-58, 2008.

[5] S. C. Yeon, J. H. Jeon, K. A. Houpt, H. H. Chang, H. C. Lee, and H. J. Lee, "Acoustic features of vocalizations of Korean native cows in two different conditions," Appli. Anim. Behavi. Sci., Vol.1, No.1-2, pp.1-9, 2006.

[6] T. Zho, R. Nevatia, and B. Wu, "Segmentation and tracking of multiple human in crowded environments," IEEE Transactions on Pattern Analysis and Machine Intelligence, Vol.30, No.7, pp.1198-1211, 2008.

[7] J. Feng, C. Zhang, and P. Hao, "Online learning with self-organizing maps for anomaly detection in crowd scenes," in Proc. of ICPR, pp.3599-3602, 2010.

[8] W. Fei and S. Zhu, "Mean shift clustering-based moving object segmentation in the H.264 compressed domain," IET Image Processing, Vol.4, No.1, pp.11-18, 2010.

[9] S. K. Kapotas and A. N. Skodras, "Moving object detection in the H.264 compressed domain," in Proc. of Image System and Technique(IST), pp.325-328, 2010.

[10] N. Kiryati, T. Raviv, Y. Invanchenko, and S. Rochel, "Real-time abnormal motion detection in surveillance video," in Proc. of ICPR, pp.1-4, 2008.

[11] R. Mehran, A. Oyama, and M. Shah, "Abnormal crowd behavior detection using social force model," in Proc. of CVPR, pp.935-942, 2009.

[12] Y. Shi, Y. Gao, and R. Wang, "Real-time abnormal event detection in complicated scenes," in Proc. of ICPR, pp. 3653-3656, 2010.

[13] S. Pathan, A. Al-Hamadi, and B. Michaelis, "Incorporating social entropy for crowd behavior detection using SVM," in Proc. of ISVC, pp.153-162, 2010.

[14] JIMS Report [Internet], http://www.limc.co.kr/

[15] T. Cao, X. Wu, J. Guo, S. Yu, and Y. Xu, "Abnormal crowd motion analysis," in Proc. of International Conference on Robotics and Biomimetics, pp.1709-1714, 2009.

[16] X. Zhang, H. Liu, Y. Gao, and D. Hu, "Detecting abnormal events via hierarchical dirichlet process," in Proc. of PAKDD, pp.278-289, 2009.

[17] V. Mahadevan, W. Li, V. Bhalodia, and N. Vasconcelos, "Anomaly detection in crowded scenes," in Proc. of CVPR, pp.1975-1981, 2010.

[18] L. Kratz and K. Nishino, "Anomaly detection in extremely crowded scenes using spatio-temporal motion pattern models," in Proc. of CVPR, pp.1446-1453, 2009.

[19] J. Ramirez, J. Gorriz, J. Segura, C. Puntonet, and A. Rubio, "Speech/non-speech discrimination combining Advanced feature extraction and SVM learning," in Proc. of 
INTERSPEECH, pp.1662-1665, 2006.

[20] D. Tax and R. Duin, "Uniform object generation for optimizing one-class classifiers," Journal of Machine Learning Research, Vol.2, pp.155-173, 2001.

[21] Y. Chung, J. Lee, S. Oh, D. Park, H. H. Chang, and S. Kim, "Automatic Detection of Cow's Oestrus in Audio Surveillance System," AJAS(Asian-Australasian Journal of Animal Sciences), Vol.26, No.7, pp.1030-1037, 2013.

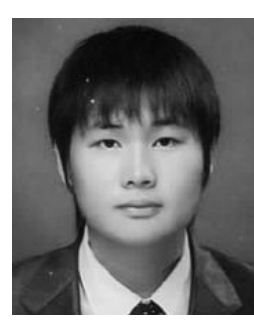

\section{오 승 근}

e-mail : gmo85@korea.ac.kr

2004년 고려대학교 컴퓨터정보학과(학사) 2010년 고려대학교 컴퓨터정보학과(석사) 2010년 현 재 고려대학교 컴퓨터정보학과 박사과정

관심분야: 패턴인식, 감시시스템

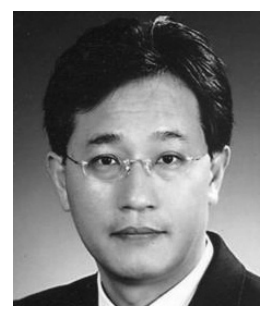

\section{박 대 희}

e-mail :dhpark@korea.ac.kr

1982년 고려대학교 수학과(학사)

1984년 고려대학교 수학과(석사)

1989년 플로리다 주립대학 전산학과(석사)

1992년 플로리다 주립대학 전산학과(박사)

1993년 현 재 고려대학교 컴퓨터정보학과

$$
\text { 교수 }
$$

관심분야: 데이터마이닝, 인공지능, 축산 IT

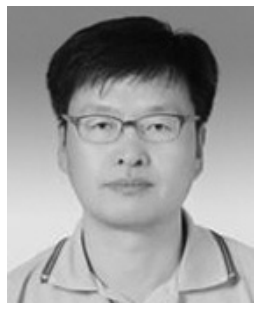

장 홍 희

e-mail : hhchang@gnu.ac.kr

1989년 충남대학교 농업기계공학과(학사) 1994년 충남대학교 농업기계공학과(석사) 1998년 충남대학교 농업기계공학과(박사) 1999년 현 재 경상대학교 축산학과 교수

관심분야: 축산시설, 동물행동

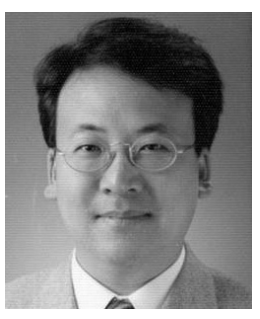

\section{정 용 화}

e-mail : ychungy@korea.ac.kr 1984년 한양대학교 전자통신공학과(학사) 1986년 한양대학교 전자통신공학과(석사) 1997년 남가주대학 전기·공학과(박사) 1986년 2003년 한국전자통신연구원 생체인식기술연구팀(팀장)

2003년 현 재 고려대학교 컴퓨터정보학과(교수) 관심분야: 영상처리, 병렬처리, 축산 IT 